MEYVECILIK ARASTIRMA ENSTITÜSÜ MÜDÜRLÜčü FRUIT RESEARCH INSTITUTE

ISSN: 2148-0036

e-ISSN: 2148-8770

Yıl /Year: 2021

Cilt(Sayı)/Vol.(Issue): 8(2) Sayfa/Page: 23-29

Derleme

Review

DOI: $10.51532 /$ meyve.1024692

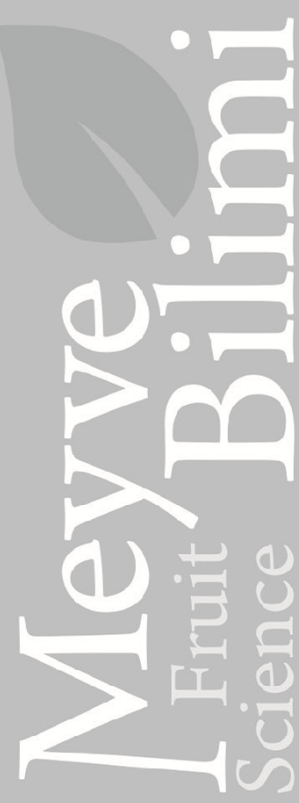

\section{Guava (Psidium guajava L.) Yetiştiriciliğine Genel Bir Bakış}

\author{
Gizem GÜLER ${ }^{* 1}{ }^{1}$, Hamide GÜBBÜK ${ }^{2}$, Berkay ÇELIK ${ }^{2}$ \\ ${ }^{1}$ Batı Akdeniz Tarımsal Araștırma Enstitüsü Müdürlüğü, Antalya \\ ${ }^{2}$ Akdeniz Üniversitesi, Ziraat Fakültesi, Bahçe Bitkileri Bölümü, Antalya \\ * gizemguler88@gmail.com (Sorumlu Yazar)
}

Özet

Guava (Psidium guajava L.), dünyada nemli tropikten subtropik koşullara kadar çok geniş bir ekolojide yetiştirilmektedir. Türkiye'de ise Akdeniz bölgesinin sahil kesiminde hobi ve kısmen de ticari olarak yetiștirilmeye başlanmıștır. Ticari yetiștiricilik, Mersin'in Silifke, Antalya'nın ise Gazipaşa ve Alanya ilçelerinde yapılmaktadır. Bununla birlikte, yola dayanımının sınırlı olması, bu meyve türünün dünyada olduğu gibi Türkiye'de de gıda endüstrisinde değerlendirilmesini gündeme getirmiştir. Gıda endüstrisinde aroma, reçel, marmelat ve meyve suyu sanayinde kullanılma şansı bulunmaktadır. Bu nedenle hazırlanan bu derlemede, guavanın morfolojik ve biyolojik özellikleri, ekolojik istekleri, önemli çeşitleri, çoğaltma yöntemleri, kültürel uygulamalar, besin değeri, kullanım alanları, sağlık açısından öne$\mathrm{mi}$, derim ve depolama konularına yer verilmiștir.

Anahtar kelimeler: Psidium guajava L., adaptasyon, ekoloji, tropik elma, vitamin C

\section{An Overview of Guava (Psidium guajava L.) Cultivation}

Abstract

Guava (Psidium guajava L.) is cultivated in a wide range of ecology from humid tropical to subtropical conditions around the world. It has started to be grown as a hobby and partly commercial in the coastal part of the Mediterranean region in Turkey. Commercial cultivation is common in the Silifke district of Mersin also Gazipaşa and Alanya districts of Antalya. However, the sensitivity for the transport has brought this fruit species to be evaluated in the food industry in Turkey as well as in the world. It can be used as flavor, jam, marmalade and fruit juice in the food industry. Consequently, in this review, morphological and biological characteristics of guava, ecological desires, important varieties, propagation methods, cultivation implementations, nutritional values, usage areas, health importance, harvesting and post harvesting technics are included.

Keywords: Psidium guajava L., adaptation, ecology, tropical apple, Vitamin C

\section{Giriş}

Guava (Psidium guajava L.), dünyada tropik ve subtropik iklim kuşağında yetiştirilme şansı olan bir türdür. Myrtaceae familyasının Psidium türü içerisinde yer alan guava, 150 tür arasında en popüler olanlarından birisidir (Samson, 1986). Vitamin ve mineraller açısından zenginliği nedeniyle "tropiklerin elması" olarak nitelendirilmekte ve tüketilmektedir. Guava, dünyanın farklı ülkelerinde farklı isimlerle anılmaktadır. İngilizce'de guava, Fransızca'da goyava, Filipince'de bayabas, Arapça'da juava, Belgalce'de goaachhi, Hawaii dilinde kuawa ve Almanca'da guava ismi ile anılmaktadır. Ayrıca meyve şekline göre; 'elma guava', 'limon guava', 'armut guava' veya üretildiği ülkelere göre 'Brezilya guava'sı', 'Gine guava'sı' gibi değișik isimler ile adlandırılmaktadır (Irshad vd., 2020).

Guava, tropikal meyveler arasında minör meyve grupları arasında yer almakta olup bu grup içerisinde en yüksek üretim payına sahip olan türdür. Guava üretimi, FAO istatistikleri ile ilgili üretim listesinde tek başına yer almamakta, mango ve mangosteen ile birlikte yer almaktadır. FAO'nun istatistiki tahminlerine göre 2019 yllı mango, mangosteen ve guava üretimi 55.8 milyon ton olarak bildirilmiștir (FAO, 2021). Bu üretimin yaklașık 6 milyon tonunun guava olduğu tahmin edilmektedir (Mitra, 2021).

Günümüzde tropik ve subtropik iklim kuşağına sahip 60'ın üzerinde ülkede yetiștiriciliği yapılmaktadır. En yüksek üretim payına sahip olan ülke Hindistan olup, bunu sırasıyla Pakistan, Brezilya, Meksika, Endonezya ve Tayland izlemektedir (Mitra, 2021). Ülkemizde ise henüz kapama bahçeler olmamakla birlikte, özellikle Akdeniz bölgesinin sahil kesimlerinde hobi ve kısmen de ticari olarak yetiş- 


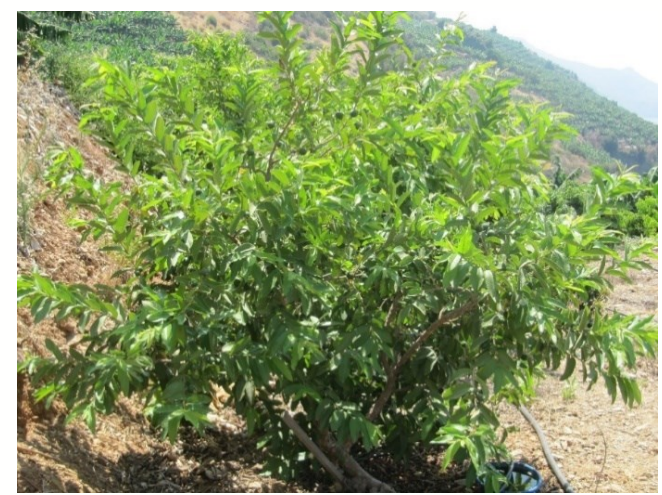

Şekil 1. Guava ağacının genel görünümü

Figure 1. General view of guava tree

tiriciliği yapılmaya başlanmış olup Mersin'in Silifke, Antalya'nın Gazipaşa ve Alanya ilçelerinde yetiştiriciliği yapılmaktadır.

\section{Morfolojik ve Biyolojik Özellikleri}

Guava; yaprağını dökmeyen, çalı formunda büyüyen, nemli koşullarda 6 - 9 m yüksekliğe kadar çok hızlı gelişebilen bir türdür. Gövdesi yeșilimsi kahverengi renkte ve kolay soyulabilir yapıdadır (Gill vd., 2016). Dalları esnek yapıda, kahverengi renge sahip olup, ağacın tepe kısmı kubbe şeklinde büyüme gösterir ve yayvan bir taç yapısına sahiptir (Irshad vd., 2020) (Şekil 1). Yapraklar oval şekilli olup, yaklaşık 7 - $15 \mathrm{~cm}$ uzunluğunda, 3 - $5 \mathrm{~cm}$ çapında ve birbirine ters yönde gelişmektedir (Şekil 2A).

Guava'da çiçeklenme zamanı iklim koşullarına bağlı olarak değişiklik göstermektedir. Ekvatora yakın iklimlerde yıl boyu çiçeklenme, ülkemiz gibi subtropik koşullarda yılda iki defa çiçeklenme görülmektedir (Normand, 2002; Gill vd., 2016). Çiçekler bir yaşlı dalların odunlaşmış sürgünlerinin yaprak koltuklarında tek veya üçlü kümeler halinde meydana gelmektedir. Çiçekler 25 - 30 mm çapında, 4 5 adet beyaz renkli petal ve 4 - 5 adet yeşil renkli sepal yapraklara ve yeșilimsi anterlere sahip olup, çiçekleri hermafrodit yapıdadır (Şekil 2B). Çiçeklerde kendine tozlanma oranı \%60-75 arasında farklılık göstermekle birlikte, yabancı tozlanma oranı \% 35 dolayındadır (Gill vd., 2016). Çiçeklenmeden hasada kadar geçen süre 120 - 220 gün arasında değişmektedir (Paull ve Duarte, 2012).

Guava meyveleri botanik açıdan üzümsü meyve
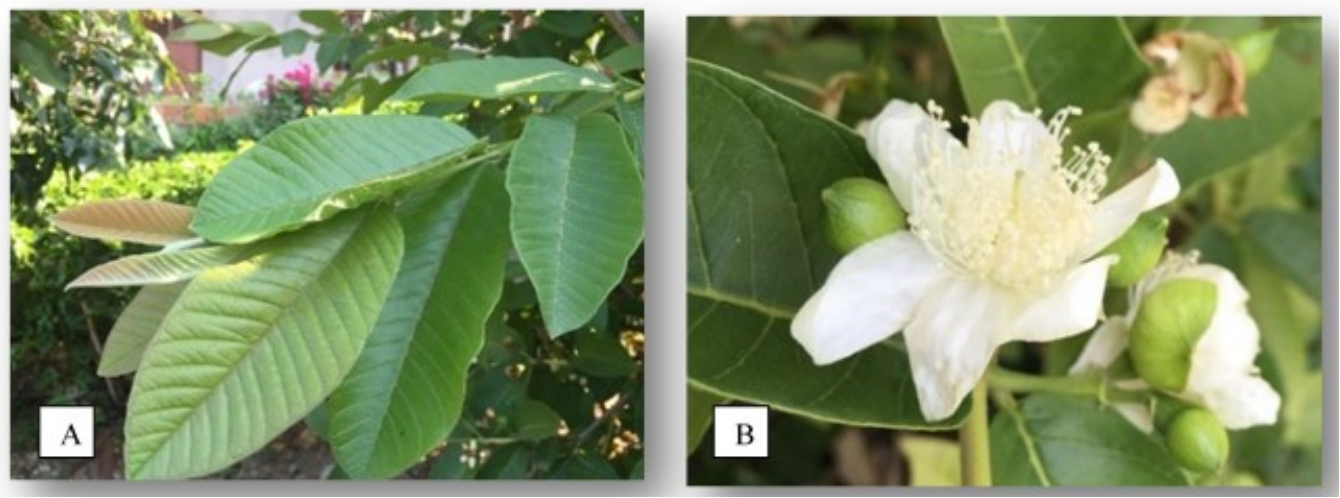

Şekil 2. Guava yaprağının (A) ve çiçeğinin (B) genel görünümü

Figure 2. General view of leaves (A) and flower (B) in guava

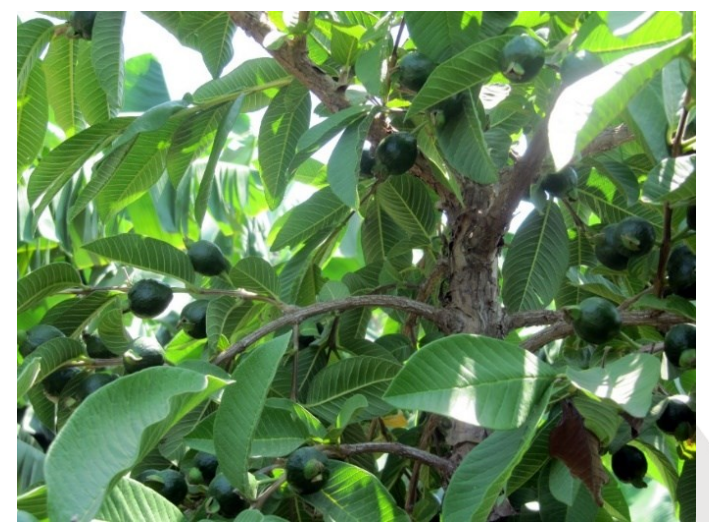

Şekil 3. Gelişmekte olan guava meyvelerinin genel görünümü Figure 3. General view of developing guava fruits grubu içerisinde yer alır. Meyveleri yuvarlak, oval veya armut şeklinde, rengi ise bașlangıçta koyu yeşildir (Şekil 3). Guava meyvesinin \%20'sini meyve kabuğu, \%50'sini meyve eti ve \%30'nu ise tohum olușturmaktadır. Olgun meyveler, içerdiği esterler ve terpenlerden dolayı güçlü ve keskin bir kokuya sahiptir (Mitra, 1997). Meyve çapı 2.5 - 10 $\mathrm{cm}$, ortalama meyve ağırlığı ise $100-400 \mathrm{~g}$ arasında değișiklik göstermektedir. Meyve kabuğu pürüzsüz bir yapıda olup, rengi açık sarı ve yeşil tonlarındadır. Meyveler olgunlaştıkça dış kabuk rengi sarıya dönüşmektedir. Meyve et rengi ise genellikle kremsibeyaz, kremsi-sarı veya pembe gibi değișik renk tonlarında olup, daha koyu kırmızıya yakın renk tonlarına da rastlanmaktadır 


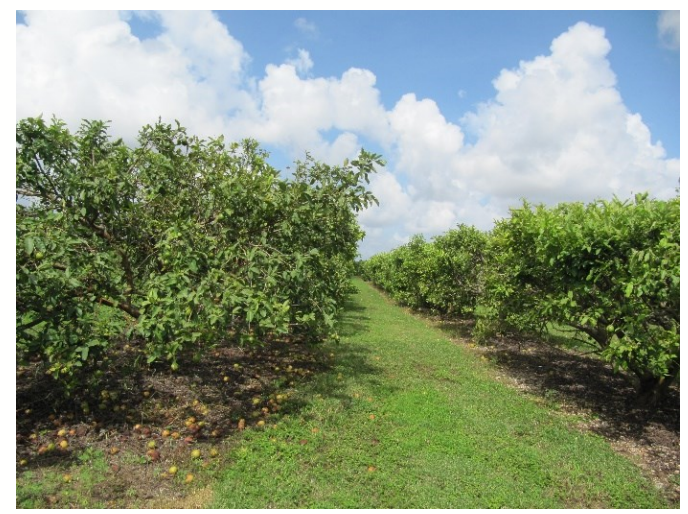

Şekil 4. Florida'da guava bahçesinden genel bir görünüm Figure 4. A general view of guava plantation in Florida

(Mitra vd., 2012; Gill vd., 2016; Irshad vd., 2020). Guava meyvesi klimakterik özellik göstermekte, genç meyveler sert yapıda ve ekşidir. Meyveler olgunlaştıkça yumuşamakta ve asit oranı düşerek tatlanmaktadır (Mitra, 2021). Guava meyvesinin içerisinde çok sayıda tohum bulunur. Tohumlar, sert ya da yarı sert yapıda olup meyve eti içerisinde gömülü halde bulunmaktadır (Yadava, 1996).

\section{3. Çeşitler}

Guavada yaklaşık 400'ün üzerinde çeşit bulunmaktadır. Ancak bu çeşitlerden yalnızca birkaçı ticari yetiştiricilikte kullanılmaktadır. Farklı ülkelerde guava yetiştiriciliği yapılan önemli ticari çeșitler Çizelge 1'de verilmiștir (Pommer vd., 2006; Singh, 2011). Guava çeşitleri üç grup altında sınıflandırılmaktadır (Menzel 1985; Jaiswal ve Amin, 1992). Birinci grup; tatlı ve asitliği düşük olan meyvelerden oluşmaktadır. Bu gruba giren meyveler çoğunlukla beyaz etli olup, 'Allahabad Safeda', 'Lucknow 49 (Sardar)' ve 'Tathem White' çeşitleri bu gruba örnek olarak gösterilebilir. İkinci grup; kırmızı ya da pembe et rengine sahip ve meyve eti oranı daha yüksek olan çeşitleri içermektedir. Bu gruptaki meyveler yüksek asitli olup, gıda sanayinde kullanılmaktadır. 'Ka Hua Kula' çeşidi bu gruba örnek olarak gösterilebilir. Üçüncü grup; işleme ve sofralık tüketime uygun tatlı çeşitlerdir. $\mathrm{Bu}$ gruba,
'Etheridge Selecction', 'Oakey Pink' ve 'Fanretief' çeşitleri girmektedir.

Ülkelere göre de çeşitler farklılık göstermektedir. Örneğin; 'Allahabad Safeda', 'Sardar', 'Red Fleshed', 'Chittidar' ve 'Nasik', Hindistan'da en tanınmış çeşitleridir. Verimli olan bu çeşitler yeme kalitesi iyi olan tatlı gruba girmektedir. Bu grupların dışında Hawaii'nin tatlı grubuna giren çeşitlerinin arasında 'Beaumont', 'Ruby Supreme' ve 'Ka Hua Kula' ve Fildişi Sahilinde ise 'Supreme' ve 'Elisabeth' en popüler çeşitler olarak gösterilmektedir (Yadava, 1996). Ayrica 'Etheridge Selection', 'Oakey Pink', 'Tathem White' ve 'Indonesian Seedless', çeşitleri önemli çeşitlerdir. Küba'nın sahip olduğu çeşitler ise bodur gelişme özelliği gösteren, armut şeklinde ve kırmızımsı pembe et rengine sahip çeşitler olup, bu gruba örnek olarak 'Roja Enana Cubana' ya da 'EAA 1840' çeşitleri gösterilebilir. Bu çeşitler taze tüketimde ya da endüstriyel olarak değerlendirilebilmektedir (Paull ve Duarte, 2012).

Guava meyveleri, tohum ya da tohumsuz yapıda olabilmektedir. Bu durum meyve iriliğini etkilemektedir. Nitekim Nagar ve Raja Rao (1983), 'Allahabad Safeda' çeşidine ait çekirdekli meyvelerin, 'Allahabad Seedless' çeşidine ait çekirdeksiz meyvelerden daha iri olduğunu bildirmişlerdir. Guava gerek taze olarak gerekse de gıda sanayinde kullanıldığından popülaritesi gittikçe artmaktadır. $\mathrm{Bu}$ nedenle yeni çeşitler ve hibritler geliștirilerek son on yılda guava üretimi artışa geçmiştir (Singh, 2011).

\section{Ekolojik İstekleri}

Guava, farklı toprak koşullarında yetiştirilebilmektedir. Bununla birlikte yetiştiricilikte, organik maddece zengin, pH'sı 5-7 arasında değişen, drenajı iyi, hafif kumlu, killi-tınlı topraklar tercih edilmelidir. En kaliteli guava meyvelerinin, verimli olarak bilinen nehir kenarlarında yetiştirildiği bildirilmiştir (Gill vd., 2016). Toprak pH'sının 5'den düşük, 7'den yüksek olması durumunda ise öncelikle çinko ve sonrasında da demir eksikliği görülebilmektedir (Paull ve Duarte, 2012). Guava, taban suyu yüksek

Çizelge 1. Farklı ülkelerde ticari yetiştiriciliği yapılan önemli çeşitler

Table 1. Important commercial guava cultivars grown in different countries

\begin{tabular}{ll}
\hline Ülkeler & Çeşitler \\
\hline Avustralya & Indonesian Seedless, Allahabad Safeda, Lucknow-49, Beaumont, Ka Hua Kula, \\
Brezilya & Paluma, Rica, Pedro Sato, Kumagai, Ogawa, Sassaoka, Yamamoto, Se'culo XXI \\
Kolombiya & Puerto Rico, Rojo Africano, Extranjero, Trujillo Costa Rica, Tai-kuo-bar \\
Küba & Enana Roja Cubana, EEA 1-23 \\
Misır & Bassateen El Sabahia, Bassateen Edfina, Allahabad Safeda \\
Hindistan & Allahabad Safeda, Lucknow-49 (Sardar), Banarsi Surkha, Apple Color, Chittidar, Nasik, Dholka, \\
& Dharwar, Habshi, Seedless, Red-Fleshed, Behat Coconut \\
Endonezya & Indonesian Seedless, Indonesian White \\
İsrail & Ben-Dov \\
Fildiși Sahili & Supreme, Elisabeth \\
Pakistan & Safeda, Allahabad, Red-Fleshed, Seedless, Karela, Apple Color \\
Tayvan & Tai-kuo-bar, Chung-Shan, Shih-Chi, Li-Tzy, Red, Jen-Ju, Shuei-Jing \\
Tayland & Glom Sali, Glom Toon Klau, Khao Boon Soom \\
ABD (Havai) & Beaumont, Ka Hua Kula, Hong Kong Pink, Indonesian Seedless \\
\hline
\end{tabular}


olan topraklara tolerans gösterebilirken, tuzlu topraklara çok hassastır (Morton 1987; Singh, 2007).

Sıcak ve nemli bölgelerde en iyi performansı göstermektedir. Yetiştiriciliğinin yapılacağı alanlarda yıllık yağıșın 600 mm'nin altında olmaması gerekir. Bununla birlikte, yıllık yağışın 1000-2000 mm arasında olması ve mevsimlere dağılımının düzenli olması gerekmektedir. Guava ağaçları gelișme, optimum çiçeklenme ve meyve verimi için yeterli miktarda neme ihtiyaç duyar. Çiçeklenme döneminde kuraklık ya da nem miktarı düştügünde meyve tutumu azaltmaktadır. Ağaçların, küçük meyve döneminde su stresine maruz kalması sonucu meyve dökümleri meydana gelebilmektedir. Așırı sulama ise aşırı vejetatif gelișmeyi arttırmaktadır (Yadava, 1996).

Guava, don tehlikesinin olmadığı deniz seviyesinden 1500 m yükseklikte bulunan bölgelerde yetiştirilebilmektedir. Yadava (1996); tarafindan gelişme ve meyve tutumu için gerekli optimum sıcaklığın $23-28^{\circ} \mathrm{C}$ olduğu bildirilmiştir. Özellikle çiçeklenme döneminde sıcaklıkların düșmesi, verimi olumsuz yönde etkilemektedir. Tropik meyve gibi düşünülse de subtropik koşullarda 1700 m yüksekliği aşan bölgelerde de yetiştirilebilmektedir. Bu özelliği ile dünyanın birçok bölgesinde yetiştirilebilme potansiyeline sahiptir. Kış aylarında, sıcaklığın uzun süreli $-2{ }^{\circ} \mathrm{C}$ 'de kalması, genç bitkilerin ölümüne neden olmaktadır (Paull ve Duarte, 2012). Gece sıcaklığı 5 $-7{ }^{\circ} \mathrm{C}$ olduğunda ise büyüme yavaşlamakta ve yapraklar morumsu renge dönüşmektedir.

\section{5. Çoğaltma Yöntemleri}

Guava, generatif (tohum) ve vejetatif (aşı, çelik vb.) yöntemler ile çoğaltılabilmektedir. Tohumla çoğaltıldığı zaman, yüksek oranda heterozigotik özellik göstermesi nedeniyle açılım meydana gelmektedir. Ayrıca, generatif çoğaltmada ağaçlar 4-5 yaşında meyveye yatarken, vejetatif olarak çoğaltıldıklarında 2-3 yaşında meyveye yatmaktadır. Bu sebeplerle ticari üretimde vejetatif çoğaltım yöntemleri kullanılmakta, tohumla çoğaltmadan sadece ıslah çalışmalarında yararlanılmaktadır (Martínez-De-Lara vd., 2004). Günümüzde guavanın çoğaltımında aşı, çelik, hava daldırması gibi vejetatif yöntemler kullanılmaktadır (Preece, 2003). Ticari guava yetiştiriciliğinin yapıldığı ülkelerin çoğunda bahçe tesisinde aşıyla üretilmiş fidanlar tercih edilmektedir (Pereira vd., 2017).

\section{Kültürel Uygulamalar}

Toprak işleme; yabancı otları uzaklaştırmak, toprağı gevşetmek, sulamayı kolaylaştırmak ve köklerinin havalandırması için yapılan kültürel bir işlemdir. Guavanın kökleri yüzlek olduğundan derin sürüm yapılmamakta ve kök sisteminin zarar görmemesine dikkat edilmelidir (Singh, 2007).

Guava ağaçlarında gübreleme işlemi, ilk iki yıl için- de 15:15:15 oranında N:P:K ile başlamaktadır. Üçüncü yıldan itibaren 12:12:17 oranında N:P:K gübrelemesi ile devam etmektedir. Guava yetiştiriciliğinde bazen çinko ve bor eksikliği ile karşılaşılmaktadır. Bu durumda ağaçlarda verim ve kaliteyi artırmak adına \%0.3 - 0.5 oranında çinko sülfat ve $\% 0.5$ boraks püskürtme şeklinde uygulanmaktadır (Singh, 2007).

Guava yağıșlı ve nemli ortamlarda iyi geliştiği için sulamaya dikkat edilmelidir. Yetiştiricilikte gerekli olan sulama suyu miktarı ve sıklığı; toprağın tipine, ekolojik koşullara, yıllık yağış miktarına ve ağaçların yaşına göre değișiklik gösterir. Dikimden sonraki ilk yıllarda genç fidanların vejetatif gelişimi için 2 -3 günde bir sulama yapılmalı, 2-5 yaşlarındaki fidanların gelişimi, optimum çiçeklenme ve meyve gelişimi için 4-5 günde bir sulama yapılmalıdır (Singh, 2007). Don tehlikesinin olduğu zamanlarda sulama yapılmamalıdır (Gonzảlez vd., 2000).

Guava yetiștiriciliğinde budama, ağaca şekil vermek ve uzun süre verim döneminde kalması için gereklidir. Ayrıca kültürel işlemler ve hasat kolaylığı için de guava ağacının budanması önemlidir. Subtropik koşullarda budama zamanı genellikle düşük kış sıcaklıklarının yaşandığı, tropik bölgelerde ise vejetatif büyümenin yavaşladığı dönemde yapılmaktadır. Ağaçlarda budama yapılmaması, ışık geçirgenliğini azaltırken, hasat, hastalık ve zararlılara karşı mücadeleyi de zorlaştırmaktadır. Bu durum, meyve verim ve kalitesini düşürmektedir (Lopes vd,, 1984).

Guava yetiştiriciliğinde hastalıklar ülkelere göre değişiklik göstermektedir. Ancak bazı hastalıklar birçok ülkede benzerlik göstermektedir. Önemli fungal hastalıklar arasında solgunluk, antraknoz, geriye ölüm, yaprak dökümü, pas, kanser ve meyve çürüklüğü gösterilebilir. Bu hastalıklar arasında en yaygın görülen hastalıklardan biri solgunluktur. Fusarium oxysporum ve Colletotrichum gloeosporioides guavada yaygın olarak görülen solgunluk hastalıklarıdır (Singh, 2007). Bu hastalıkla mücadelede farklı araştırmacılar birkaç öneride bulunulmuş olup; solgunluk gösteren ağaçlar tamamen kesilmeli ve bahçeden uzaklaştırılmalı, organik gübreleme ya da kireç uygulaması yapılmalı, optimum düzeyde azot ve çinko uygulanmalıdır. Guavada karşılaşılan diğer önemli hastalık ise antraknozdur. Bu hastalık birçok ülkede yaygın olarak görülmektedir. Antraknoz mücadelesi tam olarak mümkün olmamakla birlikte, bazı mücadele yöntemleri ile hastalık kontrol altına alınabilmektedir. Bu mücadele yöntemlerinden biri, 7 gün ara ile 3:3:50 oranında bordo bulamacı uygulamasıdır. Ayrıca bakır oksiklorür ve bakır oksit ile de hastalık önemli ölçüde kontrol altına alınabilmektedir (Misra, 2008). Bir diğer hastalık ise meyve çürüklüğüdür. Guignardia meyve çürüklüğü hastalığı, Hawaii'de özellikle meyvelerin ağaç üzerinde olgunlașıp yere düşmesi 


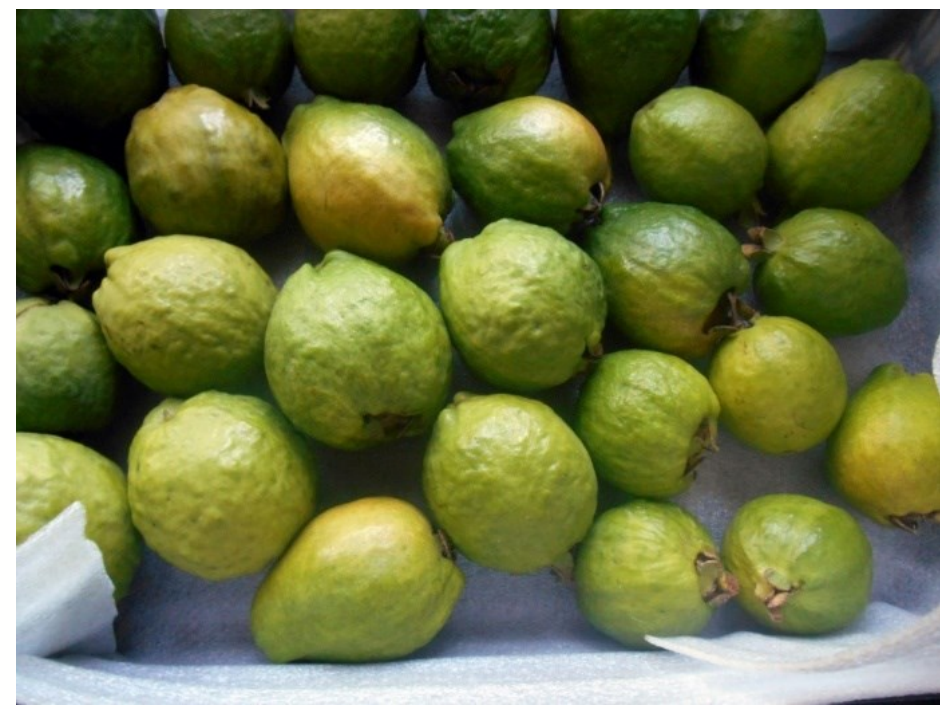

Şekil 5. Derimi yapılmış guava meyvelerinden genel bir görünüm Figure 5. A general view of harvesting fruits in guava

ile ciddi bir problem haline gelmektedir. Bu hastalıkla mücadelede, Penicillium vermoensenii'ye dayanıklı anaçlar kullanılmaktadır. Buna ek olarak, kalsiyum uygulaması da bu hastalığın mücadelesinde yaygın olarak kullanılmaktadır (Paull ve Duarte, 2012).

\section{Besin Değerleri, Kullanım Alanı ve Sağlık Açı- sından Önemi}

Guava meyvesi, düşük kalorili olup, birçok vitamin ve mineral açısından zengindir. ABD Tarım Bakanlığı ulusal besin veri tabanına (USDA) göre; $100 \mathrm{~g}$ guava meyvesinin besin içeriği; 8.92 g şeker, 228.3 mg C vitamini, 624 IU A vitamini, $0.73 \mathrm{mg}$ E vitamini, $2.6 \mu \mathrm{g}$, K vitamini, $5.2 \mathrm{mg}$ likopen (yalnızca kırmızı meyve etine sahip çeşitlerde), 417 mg potasyum, $40 \mathrm{mg}$ fosfor, $22 \mathrm{mg}$ magnezyum, $18 \mathrm{mg}$ kalsiyum olarak belirlenmiştir (USDA, 2014). Çeşitlere göre değişmekle birlikte fruktoz, glikoz ve sakkaroz türevleri şekerler meyve içeriğinde mevcuttur (Gill vd., 2016). Guava iyi bir kalsiyum ve demir kaynağ olup, fosfor açısından oldukça zengindir. Meyveleri yüksek oranda A, B1 (thiamin), B2 (riboflavin) ve C vitamini (askorbik asit) içermektedir. Guava meyvesinde bulunan $C$ vitamini turunçgillerden 2-5 kat daha fazladır (Gill vd., 2016).

Guava; antioksidan, kan şekerini düzenleme, diyabet riskini azaltma, kolesterol seviyesini azaltma, kan basıncını dengeleme, enfeksiyonu önleme, hazımsızlığı önleme ve kanserle mücadele etme özelliği ile tanınmaktadır (Gill vd., 2016). Ayrıca lif (5.4 $\mathrm{mg} / 100 \mathrm{~g}^{-1}$ ) ve karbonhidrat (14.32 $\mathrm{g} / 100 \mathrm{~g}^{-1}$ ) içeriğinden dolayı ideal bir diyet meyvesidir (Uzzaman vd., 2018). Olgunlaşmış ve olgunlaşmamış meyvelerinin tüketiminin yanı sıra, yaprak ekstraktının antimikrobiyal özelliğe sahip olduğu birçok araştırmada rapor edilmiştir. Bu avantajın- dan dolayı, çeșitli hastalıkların tedavisinde kullanılmaktadır. İçerdiği vitamin ve minerallerden dolayı cilt sağlığı üzerinde de yararlı etkileri vardır. Guava püresi ile hazırlanan cilt maskeleri cilt lekeleri, sivilce, siyah nokta ve kırışıkları ortadan kaldırmaya yardımcı olmaktadır (Uzzaman vd., 2018). Bunlara ek olarak meyve kabuğu; kusma, ülser, ishal ve dizanteri gibi hastalıkların tedavisinde kullanılmaktadır (Yavada, 1996; Uzzaman vd., 2018). Ayrica yapraklarından yapilan çaylar diyabetle mücadelede, ezilen yapraklar ise romatizma tedavisinde kullanılmaktadır (Morton 1987).

\section{Derim ve Depolama}

Guava klimakterik bir meyve türü olup, derim zamanının belirlenmesinde meyvede kabuk rengi önemlidir (Akamine ve Goo, 1979). Ayrıca derim zamanının belirlenmesinde tüketim şekli de önemli rol oynamaktadır. Örneğin, taze tüketimde meyveler tam olgunlaşmadan derilmelidir (Şekil 5). Ancak bu dönemde meyveler hassas olduğundan derim dikkatli bir şekilde elle yapılmalıdır. Endüstriyel amaçlı kullanımda ise meyveler, kabuk rengi yeşilden sarıya döndüğünde derilmelidir. Meyvelerin derimi, olgunlaşmanın yoğun olduğu dönemde 2-3 günde bir kademeli olarak yapılmalıdır. Derim zamanı gecikirse \%35-40 arasında meyve kayıpları meydana gelebilmektedir. Toplanan meyveler direkt güneșe maruz bırakılmadan depolara taşınmalıdır. Aşırı olgun, Akdeniz meyve sineği (Ceratitis capitata Wied.) zararı olan ve yere düşmüş meyveler direkt olarak imha edilmelidir (Singh, 2007).

Derimden hemen sonra taşıma sırasında fiziksel zararlanmayı önlemek için meyvelerin ya dış kısımları mutlaka bir kılıf içerisine geçirilmeli ya da meyveler büyük kutular yerine küçük kutular ile taşınmalıdır (Singh, 2007). Guava meyveleri çok çabuk bozulduğundan mümkün olduğunca çabuk tüketilmelidir. Tam derim zamanında derilen meyveler, depoda 1 hafta boyunca $7.2{ }^{\circ} \mathrm{C}$ 'de bozulmadan saklanabilir. Depolamada polietilen torbalara konan meyveler, 14 gün boyunca $8-10{ }^{\circ} \mathrm{C}$ sicaklıkta muhafaza edilebilir (Singh, 2007).

\section{Sonuç}

Guava, tropik ve subtropik iklim kuşağında birçok ülkede ekonomik olarak yetiștiriciliği yapılan bir meyve türüdür. Vitamin ve mineraller açısından zenginliği ile dünyada, Çin'den Meksika'ya kadar birçok ülkede tanınmaktadır. Taze tüketimi yanında, gıda endüstrisinde (meyve suyu, nektar, salça, 
püre ve reçel) çok yönlü kullanımı ile özellikle Avrupa ve Kuzey Amerika pazarlarında popülerlik kazanmıştır. Ülkemizde ise yetiștiriciliği henüz istenen düzeyde olmamakla birlikte, soğuklara nispeten dayanıklı olması, taze tüketimi yanında, tamamlayıcı tıpta ve gıda endüstrisinde çok yönlü kullanım olanağına sahip olması nedeniyle gelecekte bu türün yetiștiriciliğine olan ilginin artacağı düşünülmektedir.

\section{Kaynaklar}

Akamine EK, Goo T, 1979. Respiration and Ethylene Production in Fruits of Species and Cultivars of Psidium and Species of Eugenia. Journal of the American Society for Horticultural Science 10: 632 $-635$.

Baradevanal G, Rajkumar BM, Singh S, Rajan S, 2018. Pests and Their Management. In: Omkar (Eds), Pests of Guava. Springer Singapore, India, 491-516.

Chapman KR, Saranah J, Paxton B, 1979. Induction of Early Cropping of Guava Seedlings in A Closely Planted Orchard Using Urea as A Defoliant. Australian Journal of Experimental Agriculture and Animal Husbandry 19:382-4.

FAO (2021) Statistical database. http:// www.fao.org/faostat/en/\#data/QC. Accessed 25 October, 2021.

Gill KS, 2016. Encyclopedia of Food and Health Book. In: Caballero B, Finglas P, Toldrá F (Eds), Guavas. Academic Press is an Imprint of Elsevier, Oxford, 270-277.

Gonzảlez E, Padilla JS, Esquivel F, Robles FJ, Perales MA, 2000.Tecnología Para Producir Guayaba En Calvillo, Fundación Produce. Follete Para Productores. Aguas Calientes, Mexico.

Irshad Z, Hanif MA, Ayub MA, Jilani MI, Tavallali V, 2020. Medicinal Plants of South Asia. 1st Edition, Academic Press is an Imprint of Elsevier, 735pp, Pakistan.

Jaiswal VS, Amin MN, 1992. Biotechnology of Perennial Fruit Crops, Biotechnology in Agriculture. In: Hammerschlag FA, Litz RE (Eds), Guava and Jackfruit. Wallingford; CABI Publishing, UK, 421431.

Lopes JGV, Manica I, Koller OC, Riboldi J, 1984. Efecto De Seis Épocas De Poda En La Prodictión De Guayaba (Psidium Guajaba L) En Nova Hambugo. Rio Grande do Sul, Brazil. Fruits 39: 393-397.

Martínez-De-Lara J, Barrientos-Lara MC, Reyes-De Anda AC, Delgado SH, Padilla-Ramírez JS, Pérez NM, 2004. Diversidad Fenotípica Y Genética En Huertas De Guayabo De Calvillo, Aguascalientes. Revista Fitotecnia Mexicana 27 (3):243-249.
Menzel CM, 1985. Guava: An Exotic Fruit with Potential in Queensland. Queensland Agriculture Journal 111 (2):93-98.

Mitra SK, 1997. Postharvest Physiology and Storage of Tropical and Subtropical Fruits. CABI Publishing 448pp, India.

Mitra SK, Irenaeus TKS, Gurung MR, Pathak PK, 2012. Taxonomy and Importance of Myrtaceae. Acta Horticulturae 959:23-34.

Mitra SK, 2021. Guava: Botany, Production and Uses. CAB International. 384pp, India.

Morton JF, 1987. Fruits of Warm Climates. 4th Edition, 505pp, Miami.

Misra AK, 2008. Important Diseases of Guava and Their Management. National Guava Symposium, 24 -26 November 2008, 8-14, India.

Nagar PK, Raja Rao T, 1983. Endogenous Auxins in Seeded and Seedless Fruits of Guava. Scientia Horticulturae 18:323-331.

Normand F, 2002. The Strawberry Guava: A New Fruit Species for Humid Areas in Reunion Island. Acta Horticulturae 575:245-251

Paull RE, Duarte O, 2012. Tropical Fruit-Volume II. Wallingford; CAB International, 384pp, England.

Pereira FM, Usman M, Mayer NA, Nachtigal JC, Maphanga ORM, Willemse S, 2017. Advances in Guava Propagation. Revista Brasileira De Fruticultura 39 (4):228.

Pérez-Gutiérrez RM, Mitchell S, Solis RV, 2008. Psidium Guajava: A Review of It's Traditional Uses, Phytochemistry and Pharmacology. Journal of Ethnopharmacology. 117:1-27.

Pommer CV, Murakami KR, Watlington F, 2006. A Goiaba No Mundo. O Agrono^mico 58:22-26

Preece JE, 2003. A Century of Progress with Vegetative Plant Propagation. American Society for Horticultural Science, Alexandria. 38 (5):1015-1025.

Rajan S, Hudedamani U, 2019. Genetic Resources of Guava: Importance, Uses and Prospects. Springer Singapore.

Samson JA, 1986. Tropical Fruits. Tropical Agricultural Series, Longman. 336 pp, The Netherlands.

Singh G, 2007. Recent Development in Production of Guava. Acta Horticulture 735:161-176

Singh SP, 2011. Post-Harvest Biology and Technology of Tropical and Subtropical Fruits. In: Yahia EM (Eds), Guava (Psidium guajava L.). Cambridge Woodhead Publishing, UK, 213-45.

USDA, 2014. National Nutrient Database for Standard. https://www.usda.gov/ Accessed 25 October, 2021. 
Uzzaman S, Akanda KM, Mehjabin S, Parvez GMM, 2018. A Short Review on A Nutritional Fruit; Guava, Toxicology and Research 1 (1):1-8.

Yadava UL, 1996. Progress in New Crops. In: Janick J (Eds), Guava Production in Georgia under ColdProtection Structure, ASHS Press, United States of America, 451-457. 